\title{
Enabling Better Physical Activity and Screen Time Behaviours for Adolescents from Middle Eastern Backgrounds: Semi-Structured Interviews with Parents
}

\author{
Nematullah Hayba*(D), Yumeng Shi $(\mathbb{D}$ and Margaret Allman-Farinelli (D) \\ Discipline of Nutrition and Dietetics, Charles Perkins Centre, University of Sydney, Sydney 2006, Australia; \\ yshi7693@uni.sydney.edu.au (Y.S.); margaret.allman-farinelli@sydney.edu.au (M.A.-F.) \\ * Correspondence: nhay6592@uni.sydney.edu.au; Tel.: +61-468-786-039
}

check for

updates

Citation: Hayba, N.; Shi, Y.; Allman-Farinelli, M. Enabling Better Physical Activity and Screen Time Behaviours for Adolescents from Middle Eastern Backgrounds: Semi-Structured Interviews with Parents. Int. J. Environ. Res. Public Health 2021, 18, 12787. https:// doi.org/10.3390/ijerph182312787

Academic Editors: Jeffrey S. Hallam and Joanna Mazur

Received: 28 October 2021

Accepted: 26 November 2021

Published: 3 December 2021

Publisher's Note: MDPI stays neutra with regard to jurisdictional claims in published maps and institutional affiliations.

Copyright: (C) 2021 by the authors. Licensee MDPI, Basel, Switzerland. This article is an open access article distributed under the terms and conditions of the Creative Commons Attribution (CC BY) license (https:/ / creativecommons.org/licenses/by/ $4.0 /)$
Abstract: The unrelenting obesity pandemic in Middle Eastern (ME) adolescents living in Australia warrants culturally responsive and locally engineered interventions. Given the influence of parents on the lifestyle behaviours of adolescents, this qualitative study aimed to capture the opinions of ME parents on the barriers and enablers to sufficient physical activity and limiting screen time behaviours in adolescents. Semi-structured interviews were conducted with $26 \mathrm{ME}$ parents (female) aged $35-59$ years old, most of whom resided in lower socioeconomic areas $(n=19)$. A reflexive thematic analysis using the Theoretical Domains Framework and the Capability, Opportunity, MotivationBehaviour model was performed for coding. Parents voiced confidence in their knowledge of the importance of physical activity and limiting screen time but were less optimistic in their ability to enable change in behaviours, especially for older adolescents without outside support. Despite adolescents having the necessary skills to engage in a wide array of sports, the parents admitted deep fears regarding the safety of the social environment and restricted their children's independent mobility. Gender differences were noted, with parents reporting older girls expressing disinterest in sports and having limited physical opportunities to participate in sports at school. It may be that a community-based participatory framework is needed to improve physical activity opportunities and to address specific physical, social, and cultural barriers.

Keywords: adolescents; parents; interviews; physical activity; screen time; obesity; overweight; prevention interventions; ethnic minority

\section{Introduction}

The continuing burden of obesity [1] is not shared but is concentrated in populations from ethnic and racial minority backgrounds [2] and lower education and income levels [3]. This is reflected internationally, where youth such as non-Hispanic black (22\%) and Hispanic (26\%) youth in the United States (US) exhibit a higher obesity prevalence compared to those from non-Hispanic white backgrounds (14\%) [4]. Similarly, an analysis of the UK Millennium Cohort Study revealed that Black Caribbean males were three more times likely to be overweight and to have a significantly higher BMI than white adolescents. Black African females were also found to have a significantly higher BMI than white females [5]. A series of population data has shown ethnicity to be an independent mediator of unhealthy weight in children [6]. Despite these trends, obesity prevention research is lacking in recruiting adolescents from ethnic minorities [7] and/or in analysing and reporting findings by ethnic group. Furthermore, the majority of interventions have failed to produce sustained weight management [8].

In Australia, the most recent extensive survey conducted in the most populated state New South Wales (NSW) revealed that more than one quarter $(27.4 \%)$ of adolescents aged 13 to 16 years old from secondary schools were categorised as being overweight or obese [9]. More importantly, the prevalence was exacerbated in specific ethnic groups, with almost 
half of the adolescents from Middle Eastern (ME) cultural backgrounds (41.1\%) having a body mass index in the overweight or obese category compared to those from English speaking backgrounds (26.1\%) [9]. The survey also indicated that adolescents from ME backgrounds were less likely to meet key physical activity and screen time targets, resulting in less adolescents reaching the Healthy Fitness Zone (39\% vs. $61 \%$ ), an increased lack of awareness of recommended daily screen time limits (36\% vs. $58 \%$ ), and more frequent eating in front of the television ( $37 \%$ vs. $19 \%$ ) compared to those from English-speaking backgrounds [9]. In the US, almost $92 \%$ of Hispanic/Latino youth were insufficiently active and were well below the national recommendations and spent more than two hours per day on screen time [10].

Lifestyle interventions targeting adolescents are essential to favourably alter the trajectory towards adult obesity and to prevent chronic disease. Physical activity behaviours have been shown to track into adulthood [11], with lower levels linked with a predisposition for overweight and obesity as well as for other co-morbidities [12] and risk factors such as hypertension [13]. Furthermore, there is preliminary evidence supporting exercise-focused interventions for adolescents [8].

Adolescence provides a key window of change for the mitigation of risk factors and enablement by positive lifestyle interventions [14] to overturn the current early onset of chronic disease and adult obesity [12]. Although adolescents experience growing independence and autonomy from the family unit, parents are important stakeholders in shaping behaviour and in determining the home environment [15] and physical activity behaviours [16-19]. For example, population data have shown that parenting practices such as having no screen time rules were associated with overweight and obesity in adolescents [20]. Hence, in the pursuit of a culturally nuanced and effective lifestyle intervention, parents are important collaborators to inform the current adoption of physical activity and screen time behaviours in adolescents. Currently little is known about how ME parents see their role and ownership of programs to improve physical activity levels, limit screen time, and modify other lifestyle factors.

The Capability Opportunity and Motivation Behaviour Model (COM-B) [21] and the Theoretical Domain Framework (TDF) [22] were selected as the overarching theories of change to guide this study. The COM-B Model postulates that the performance of a behaviour is the result of the interaction between the person's capability (psychological and physical), opportunity (physical and social), and motivation (reflective and automatic) [21]. The TDF puts forward 14 sub constructs that are used in conjunction, further illuminating the driving factors for each COM-B domain [22].

Hence, this exploratory study aimed to capture the perceptions and practices of the Middle Eastern parents of adolescents that may enable or prove to be barriers to their children's physical activity behaviours and screen time behaviours. In particular, we sought to determine the current level of knowledge and concern about amounts of physical activity and sedentary behaviours as well as the physical environment and social supports that might prohibit or enable physical activity for this group. The parents' opinions on possible intervention programs were probed.

\section{Materials and Methods}

\subsection{Study Design}

This exploratory study with parents of adolescents from ME backgrounds aimed to capture information on physical activity and screen time behaviours using semi-structured interviews. Information on food behaviours and parent perceptions of the obesity pandemic were also captured but reported elsewhere [23]. This qualitative study design was selected as it enabled in-depth opinions to be shared by participants in addition to its established high validity and reliability [24,25]. The Consolidated Criteria for Reporting Qualitative Research (COREQ) [26] was used to report on this study. This study was approved by the University of Sydney Human Research Ethics Committee (2020/708). 
Two complementary behavioural frameworks were selected to guide the interview questions and subsequent coding and analysis. The COM-B model predicates that three factors and their interaction are needed for a behaviour to be performed-capability, opportunity, and motivation [21]. These are then further classified into six domains: psychological capability, physical capability, physical opportunity, social opportunity, automatic motivation, and reflective motivation. This model allows researchers to identify which components need to be altered in order to elicit the targeted behaviour [27]. Greater insight is afforded with the use of the TDF [22,28,29], which presents 14 domains that readily correspond to the domains of the COM-B model. Table 1 presents a diagrammatic summary of the inter-related frameworks. Hence, initial data analysis conducted via COM-B was further enriched by the use of the TDF.

Table 1. Thematic framework informed by the Capability, Opportunity, and Motivation Model of Behaviour and the Theoretical Domains Framework.

\begin{tabular}{cc}
\hline Behaviour/COM-B Component & TDF Domains \\
\hline Psychological Capability & Knowledge \\
& Cognitive and Interpersonal Skills \\
Behavioural Regulation
\end{tabular}

\subsection{Participants and Recruitment}

Eligible participants were recruited via purposive and snowball sampling. Individuals that fulfilled the following criteria: (1) Parent to a teenager aged 13-18 years old; (2) of Middle Eastern background; (3) an Australian resident; and (4) able to provide informed consent, were invited to participate in the study. Recruitment flyers were shared on social media platforms such as Facebook, Instagram, and WhatsApp, making it available to existing public groups, friends, and connections within the networks of the researchers. Recruitment flyers were also posted on public noticeboards in the local government area and were distributed in areas where parents of Middle Eastern backgrounds congregate, e.g., local community and recreation centres. Passive snowball techniques were exclusively used, whereby eligible participants who had signed up informed others about the study. Participants who were interested were able to scan a QR code that was included on the flyer that redirected them to a screening questionnaire on the Research Electronic Data Capture (REDCap, Vanderbilt University, Nashville, TN, USA, 2004). If eligible, they continued on to complete a short demographic questionnaire that collected information on the number of children aged 13-18; the age of their children; the parent's age, postcode, email, and gender; and if the participant was a single parent. The socioeconomic status of the participants was determined by cross-referencing the postcodes of the participants against the Socio-Economic Indexes for Areas (SEIFA) as listed by the Australian Bureau of Statistics (ABS) [30]. Upon completion, the participants were sent an automatic email with the participation information statement and consent form attached. All participants provided consent and were contacted by one researcher $(\mathrm{NH})$ who organized the dates and times for the interviews to be conducted via telephone or Zoom, as chosen by the interviewee. The interviews were conducted from the 16 November 2020 to 28 July 2021. 


\subsection{Procedure and Data Collection}

The semi-structured interviews, which ran for about $60 \mathrm{~min}$, were conducted by the lead researcher $(\mathrm{NH})$, a female accredited practicing dietitian and $\mathrm{PhD}$ candidate who is of Middle Eastern background. The interviews used a guide of 35 questions for physical activity and screen time (100 questions on nutrition and obesity have previously been reported) [23], which were developed a priori (Table 2). The questions were determined through the agreement of two researchers (NH and MAF) and were structured based on the COM-B [21] model and the TDF $[22,27,28,31]$. Sample size was not defined a priori; rather, we aimed to conduct sufficient interviews to obtain a rich data set based on the concept of information power [32].

Table 2. Questions used in interviews to gather information on the capabilities, opportunities, and motivations of parents on adolescent physical activity and screen time behaviors.

\begin{tabular}{|c|c|}
\hline Study Topic & Questions \\
\hline $\begin{array}{l}\text { Target Behaviour: Physical } \\
\text { Activity and Leisure } \\
\text { Screen Time }\end{array}$ & $\begin{array}{l}\text { What do you think about the amount of time your child spends on the screen? } \\
\text { How about time spent on physical activity? } \\
\text { Have you ever heard excessive screen time might be associated with weight gain because the } \\
\text { children are sedentary and not physically active? } \\
\text { Do you have any rules about screen use with your children? } \\
\text { Do you have any rules about time they spend being physically active? } \\
\text { Does your child participate in any sports outside of school? } \\
\text { Does your child enjoy physical activity? } \\
\text { Do you impose limits on screen time? } \\
\text { Are there any times that you take away devices to reduce screen time? } \\
\text { Do you encourage physical activity? } \\
\text { Do you see you have an important role to play in moderating your child's screen time? } \\
\text { Do you believe that you have an important role in encouraging physical activity? } \\
\text { If not, do you think that you should? } \\
\text { What might be your plan in this area? } \\
\text { If you were to rate from } 1 \text { to } 10 \text { on how important/relevant screen time is, what would you say? } \\
\text { If you were to rate from } 1 \text { to } 10 \text { on how important physical activity is, what would you say? } \\
\text { What do you think will happen with your child's mental and physical health if they have excessive } \\
\text { screen time? } \\
\text { What do you think is a reasonable amount of screen time? } \\
\text { What do you think will happen with your child's mental and physical health if they do not have } \\
\text { enough physical activity } \\
\text { What do you think is a necessary amount of physical activity per week? } \\
\text { Does your child's screen time affect you emotionally? } \\
\text { Does your child's time participating in physical activity affect you emotionally? } \\
\text { Are there any conflicts regarding screen time? } \\
\text { How does this affect you and your child? } \\
\text { Do you enforce any routines around screen time? } \\
\text { Do you enforce any routines around physical activity? } \\
\text { Ho you give any punishments or rewards for following the screen time rules? } \\
\text { How confident are you that having less screen time will have a benefit for your child } \\
\text { How important confident are you that having more physical activity will benefit your child? } \\
\text { Does this affect your ability to encourage physical activity? }\end{array}$ \\
\hline
\end{tabular}

Time was allocated at the beginning of the interview to allow for a brief introduction and rapport building. Participants were reassured that their personal data would be kept secure and de-identified, and final consent was obtained before the recording of the session. Questions were asked regarding enablers and barriers on physical activity and screen time 
practices. Upon the completion of the interview, the participants were reimbursed with an \$20 (AUD) voucher for their time.

\subsection{Data Analysis}

All sessions were digitally audio-recorded and transcribed verbatim by one researcher $(\mathrm{NH})$. A two-step transcription process was employed to minimise errors, with a second hearing to correct any errors if present. Transcripts were not returned to the study participants. Data such as the transcriptions and audio data files were stored on the Research Data Store (RDS, University of Sydney, Sydney, Australia, AU, 2020/21). Deidentified transcripts were imported into the NVivo Pro (12th Edition, QSR International, Doncaster, Australia, 2018) qualitative data analysis software for thematic analysis. A reflexive thematic analysis was used to construct the coding framework, which consisted of a combination of deductive (themes arising from the interview questions) and inductive approaches (themes emerging from the data during analysis). Data were analysed through the following five steps, which were in line with the framework method, where (1) the transcripts were examined independently (NH, YS); (2) initial themes were constructed independently using the COM-B subcomponents and 14 TDF domains (NH, YS); (3) the themes and organizing data under each relative theme and sub-theme were coded $(\mathrm{NH}$, YS); (4) the themes were reviewed and refined (NH, YS, MAF); and (5) the data were summarised and reviewed using representative quotes $(\mathrm{NH})$.

\section{Results}

Of the 58 participants who were interested in completing the screener questionnaire, 57 were eligible. Of the 57,26 agreed to be interviewed. Reasons for not participating included inability to reach a mutual time and a non-response from those interested postsign up. It should be noted that interviews were conducted at times during government lockdowns because of the COVID-19 pandemic, which could have contributed to the non-response rates. Participants were recruited from November 2020 to July 2021. The lead researcher continued to recruit participants until it was determined that no new topics were emerging from the interviews being conducted and an information-rich data set was obtained. The duration of the interviews ranged from $40 \mathrm{~min}$ to $1 \mathrm{~h}$ and $33 \mathrm{~min}$ and covered nutrition behaviours, as reported elsewhere [33], as well as the questions regarding physical activity and sedentary, which comprised $30-40 \%$ of the interview. All of interviews were conducted in English, except for one parent, who was more comfortable speaking in a combination of Arabic and English. All of the parents were female, and the majority of mothers were from low to middle SES areas $(\mathrm{n}=19)$, as determined by the SEIFA, aged $40-49$ years of age $(n=17)$, not a single parent $(n=21)$, and the parent to one or two adolescents $(n=20)$ aged 13-14 years $(n=14)$. During the interviews, it was found that a majority of mothers were of the Islamic faith and were of a Lebanese background although no information was specifically asked during the interviews.

The findings are summarised below under the six domains of the COM-B model and subthemes from the TDF with representative quotes presented in Table 3. No part of the interview was coded to Psychological Capability for Memory, Attention, and Decision Processes and Reflective Motivation for Intentions and Beliefs about Capabilities. 
Table 3. Representative quotes from parents by key theme.

\section{Psychological Capability: Knowledge}

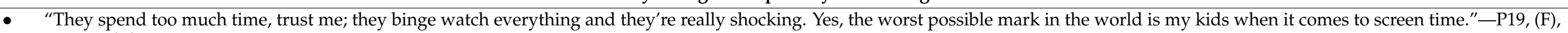
$45 \mathrm{y}, 1$ adolescent

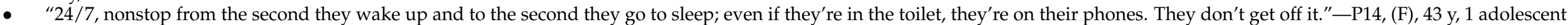

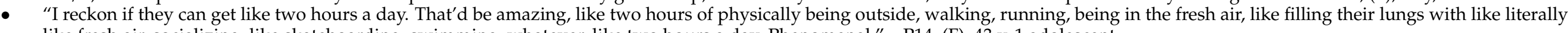
like fresh air, socializing, like skateboarding, swimming, whatever, like two hours a day. Phenomenal." - P14, (F), 43 y, 1 adolescent

- "When they're sitting on the Xbox all day. There is no exercise; the only any exercise they do is their voicebox." (laughter) - P8, (F), 46 y, 1 adolescent

\section{Psychological Capability: Behaviour Regulation}

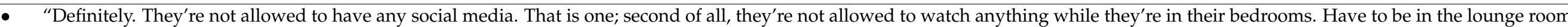

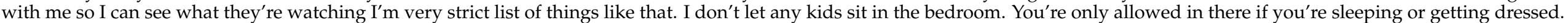

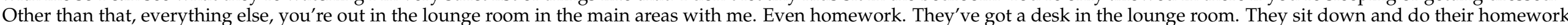
on."-P5, (F), 37 y, 1 adolescent

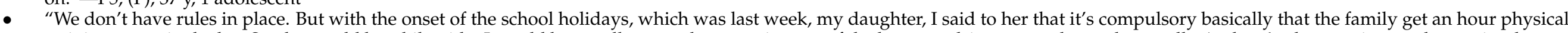

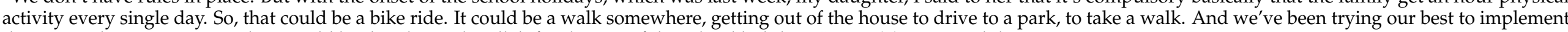
that as much as we can. But that would be the plan inshaAllah for the rest of the school holidays."-P7, (F), 42 y, 1 adolescent

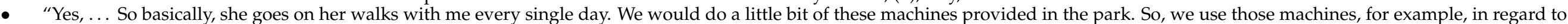
doing cycles and whatever we need to do. But she does a daily activity of at least forty to an hour every single day." - P4, (F), $32 \mathrm{y},>1$ adolescent

\section{Psychological Capability: Cognitive Skills}

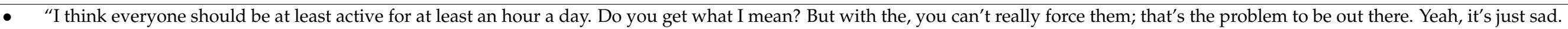
So, I don't know. It's hard."-P19, (F), 45 y, 1 adolescent

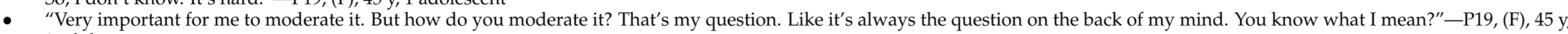
1 adolescent

\section{Physical Capability: Physical Skills}

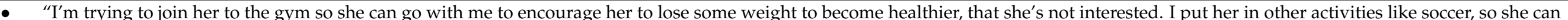

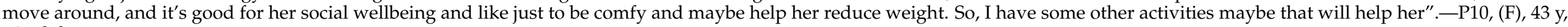
$>1$ adolescent

- $\quad$ "So, tennis every Monday and Tuesday; every Thursday and Friday, they do martial arts, and on Saturdays, swimming".-P16, (F), 38 y, 1 adolescent

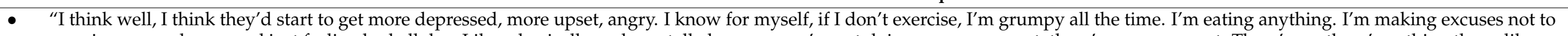

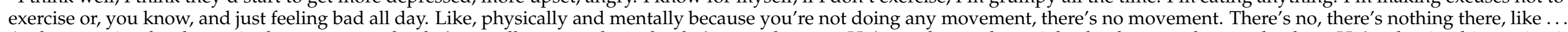

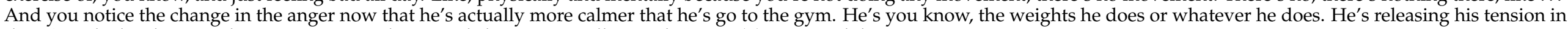
that. So, which is better. Like, you see a complete mood changes as well so yeah."-P8, (F), 46 y, 1 adolescent

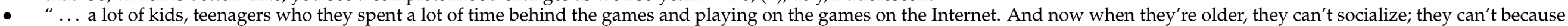

people they can't socialise because of that. Because of that, they feel they are antisocial."-P20, (F), $41 \mathrm{y},>1$ adolescent

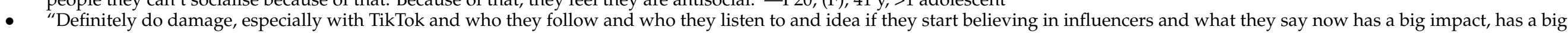
impact on them."-P17, (F), $43 \mathrm{y},>1$ adolescent 
Table 3. Cont.

\section{Reflective Motivation: Social/Professional Role and Identity}

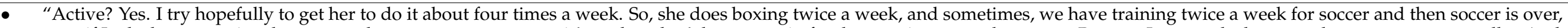

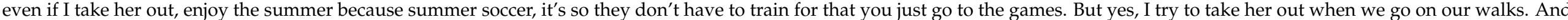

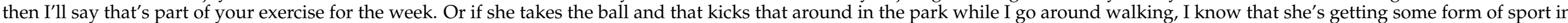
then I'll say that's part of your exercise for the week.
there or exercise. Yep."-P9, (F), 42 y, 1 adolescent

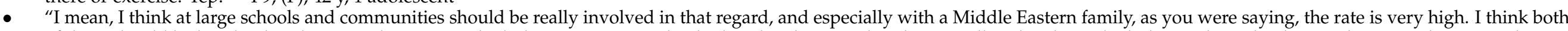

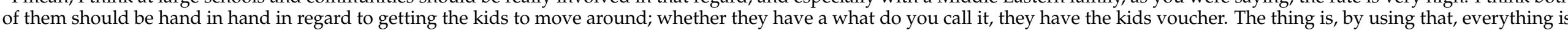

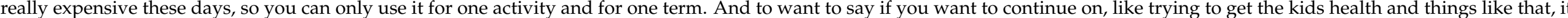

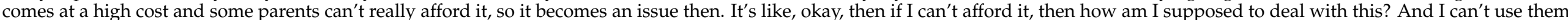

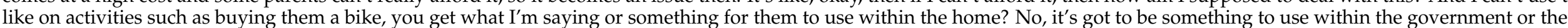

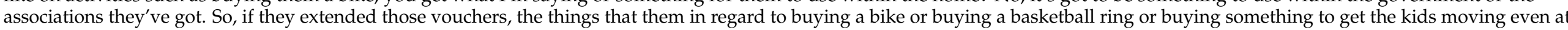

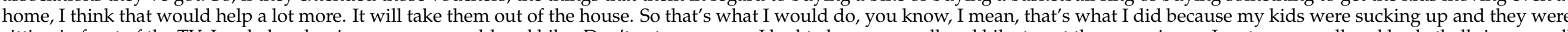

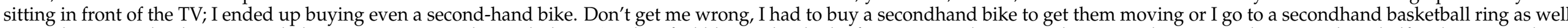

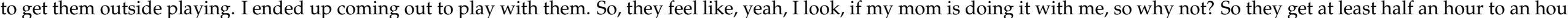

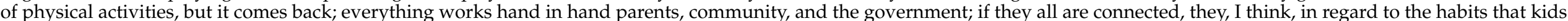
develop and things like that becomes a lot easier to deal with." - P4, (F), 32 y, >1 adolescent

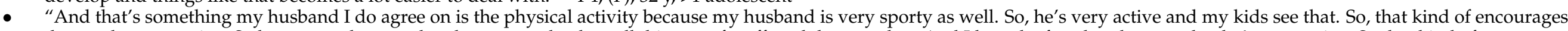

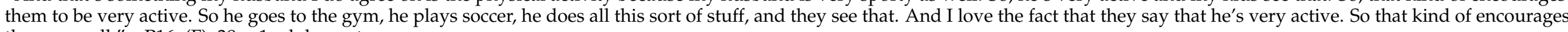
them as well."-P16, (F), 38 y, 1 adolescent

\section{Reflective Motivation: Goals}

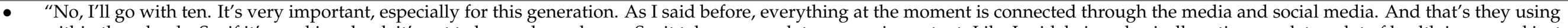

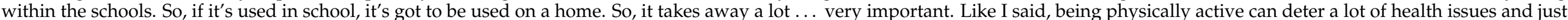
maintaining a good body weight and so helps with the growth as well and things like that. So, I think it's very important. Yes." - P4, (F), $38 \mathrm{y},>1$ adolescent

\section{Reflective Motivation: Optimism}

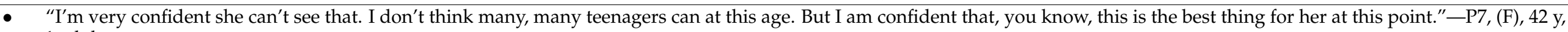
1 adolescent

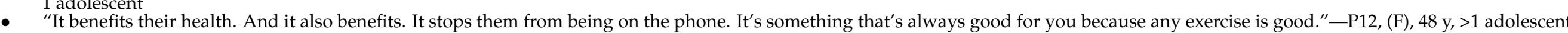

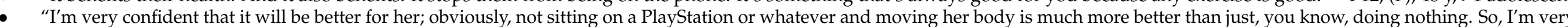

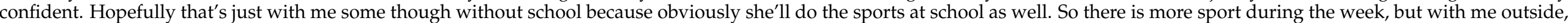
actually, I'd say more than five hours a week."-P9, (F), 42 y, 1 adolescent 
Table 3. Cont.

\section{Automatic Motivation: Emotion}

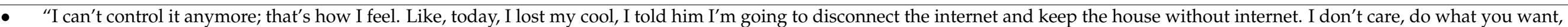

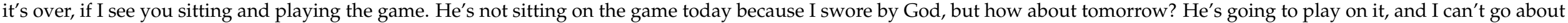

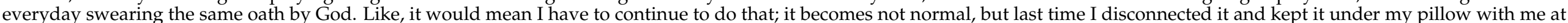
night, so he told me I'm not going to do anything. I'm not going to study. I told him don't study, it's your loss. I don't care." -P26, (F), 55 y, >1 adolescent

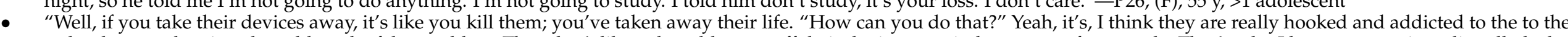

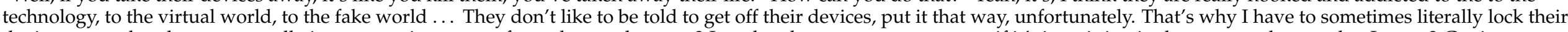

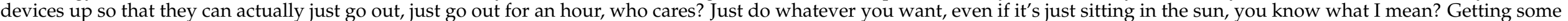

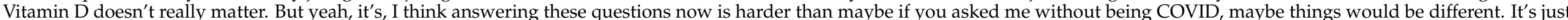
yeah, it's difficult."-P19, (F), 45 y, 1 adolescent

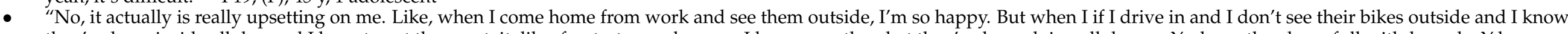

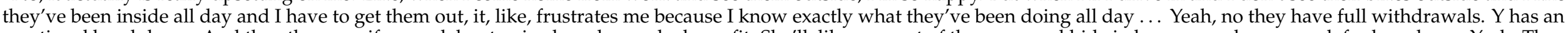

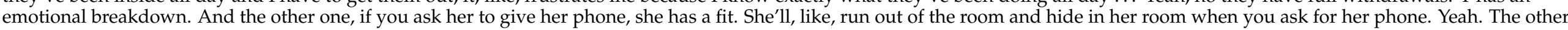

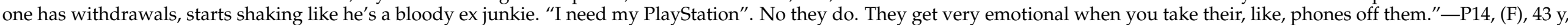
1 adolescent

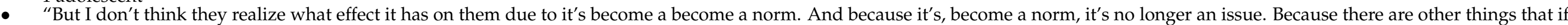

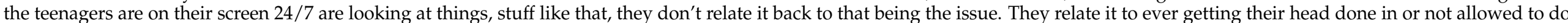
something, or do you know what I mean? So, it becomes other things, become mental, it's not the screen time; the screen time is an escape for them." -P11, (F), $45 \mathrm{y}$, $>1$ adolescent

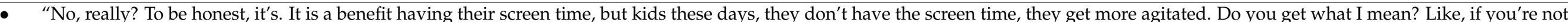

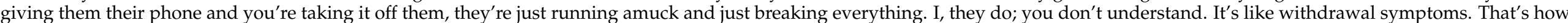
I see it. Like, phones these days, they're pretty. I think they've been addicted to it." - P12, (F), 48 y, $>1$ adolescent

\section{Automatic Motivation: Reinforcement}

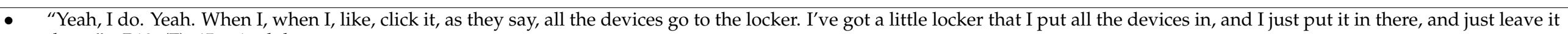
there."-P19, (F), $45 \mathrm{y}, 1$ adolescent

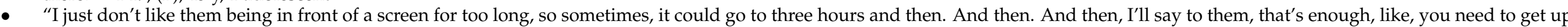

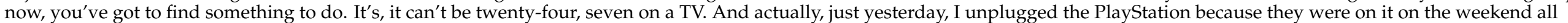

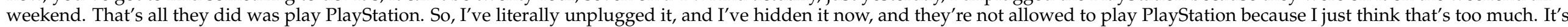

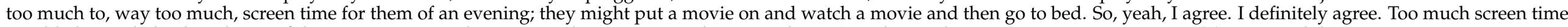
would obviously lead to obesity if they're not going to be active and getting up or doing anything. So, I do put the time restrictions on" - P16, (F), 38 y, 1 adolescent 


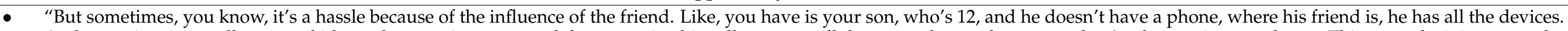

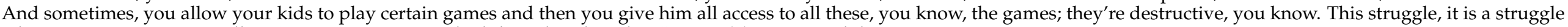
when it comes to games really; it's not easy to put a schedule and stick with it."-P22, (F), 50 y, $>1$ adolescent

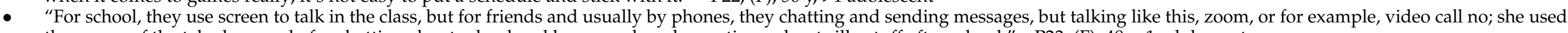
the screen of the telephone only for chatting about school and homework and sometimes about silly stuff after school." - P23, (F), 48 y, 1 adolescent

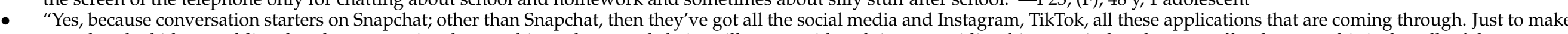

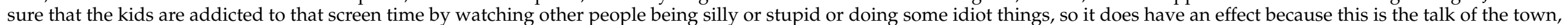
basically. What are you watching? What are you doing? Have you seen this? Have you seen that? Yep. So, it plays a massive role." - P4, (F), $32 \mathrm{y},>1$ adolescent

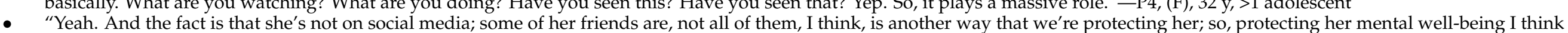

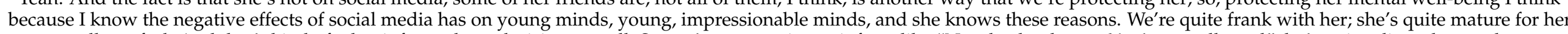

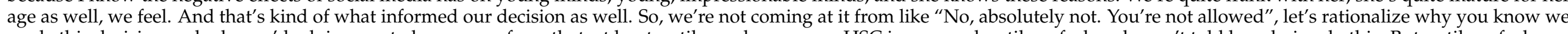

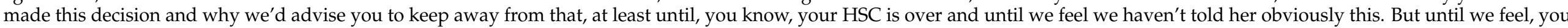

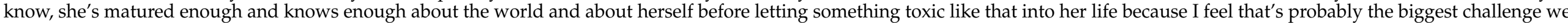

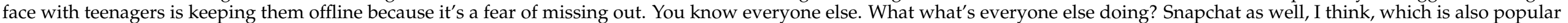

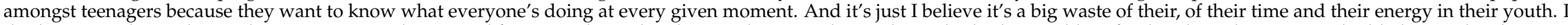

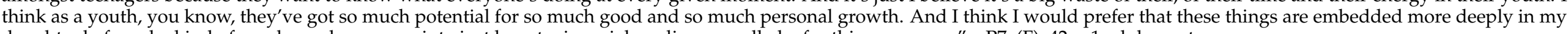
daughter before she kind of you know has an eye into just how toxic social media can really be for this age group." - P7, (F), 42 y, 1 adolescent

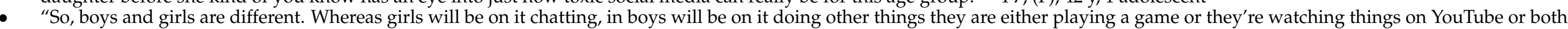

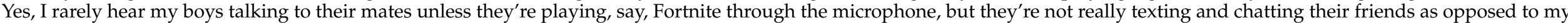
daughter is."-P17, (F), $43 \mathrm{y},>1$ adolescent

\section{Physical Opportunity: Environmental Context and Resources}

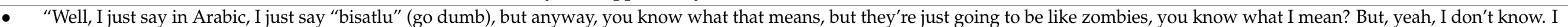

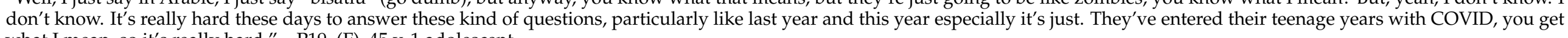
what I mean, so it's really hard."-P19, (F), 45 y, 1 adolescent

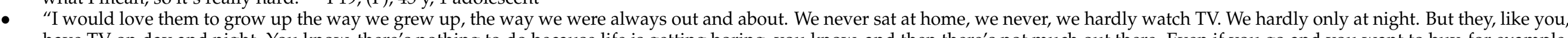

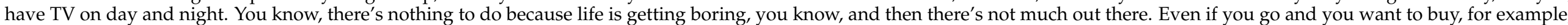

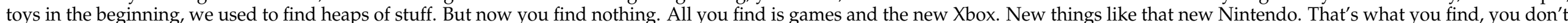
find something that their child can use their brain for."-P11, (F), $45 \mathrm{y},>1$ adolescent

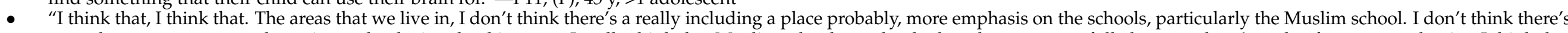

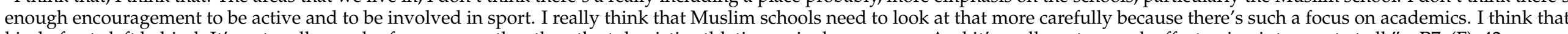
kind of gets left behind. It's not really much of a concern other than the tokenistic athletic carnival every year. And it's really not enough effort going into sport at all."-P7, (F), 42y, 1 adolescent

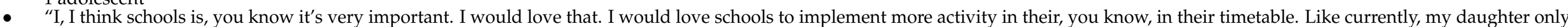

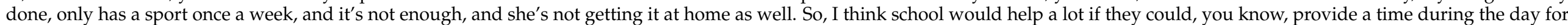

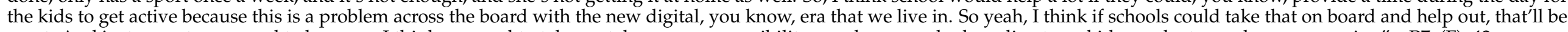
great. And just parents, we need to be more, I think we need to take up take more responsibility, you know, and, uhm, direct our kids maybe towards more exercise."-P7, (F), 43 y, $>1$ adolescent 


\subsection{Psychological Capability}

\subsubsection{Knowledge}

Physical activity: Parents expressed a high level of awareness of the need for the adoption of healthy physical activity behaviours in adolescents, irrespective of absence or presence of weight concerns. However, parents were concerned over lack of physical activity (PA), especially in girls and later age adolescents. Physical movement in adolescents was largely attributed to extracurricular organised sports such as $\mathrm{Oz}$ tag, basketball, swimming, and soccer 1-2 times per week. Such activities usually demanded extra time for the maintenance of physical endurance and strength, which was completed via gym and training sessions $2-3$ times a week, which was mostly reported in boys. Parents were eager for participation, claiming at least half an hour to one hour per day should be dedicated to PA. One parent relayed that $15 \mathrm{~h}$ per week of PA by their adolescents would be substantial to meet physical activity guidelines.

Screen time: The mothers demonstrated great apprehension over excessive screen time and were aware of the link between excessive screen time and weight gain because of lack of physical activity. Whilst excessive screen time was linked to several devices such as TVs and iPads, smartphones were the most ubiquitously used and the most frequent source of extended periods of leisure screen time. The mothers claimed that adolescents were addicted, with at least $2-3 \mathrm{~h}$ a day spent consumed with their smartphones. Many reported several hours a day, reaching $8 \mathrm{~h}$ or more during holidays, a number that was exacerbated by the COVID-19 pandemic. In addition to health concerns, the parents had intimate knowledge of the dangers of social media, a major source of worry. The parents affirmed that if they were able to exact influence on leisure screen time, they would limit it to $1 \mathrm{~h}$. For the majority of parents, this remained elusive in the context of the digital revolution and the inherent and prevalent use of screen devices.

\subsubsection{Behavioural Regulation}

Physical Activity: The parents aimed to increase physical activity by introducing at least half an hour per day of activities after school and signing their children up for extracurricular sporting activities; however, this was more successful in boys. Girls who did listen and take part in sports usually attended the gym with theirs parents and friends and joined boxing classes. The parents also tried to take their children to the park when they were free to encourage at the very least walking.

Screen Time: The parents demonstrated multiple regulatory strategies to limit screen time and content. This included only allowing phones once they reached 14/15 years of age, enabling child-friendly settings on devices, banning social media, or limited access using the mother's phone and social media accounts. Some parents did not allow the devices to be taken to school, and the majority set a schedule during the week to minimise screen time. They also ensured that they had passwords to devices and made sure to monitor their use, encouraging their children to use devices in open rooms such as the living room, especially for girls. Some also had curfews, where the adolescents handed in their devices before retiring for the night.

\subsubsection{Cognitive Skills}

The parents displayed various skills in helping to mitigate excessive screen time and content, including child-friendly settings and set times, but expressed the need for parental support in maintaining these rules, especially for older adolescents who had more independence and who were more likely to carry a smartphone. The COVID-19 pandemic as well as the abilities of a smartphone to be used for watching, gaming, and communicating with their friends rendered any regulatory efforts fruitless. 


\subsection{Physical Capability}

Physical Skills

The parents reported that their children displayed the necessary skills to engage in all sorts of physical activity whether it be gym sessions or organised sporting activities. They did however express concerns over a decline in physical skills due to excessive screen time behaviours. Most parents had to initially encourage their children to partake in PA opportunities.

\subsection{Reflective Motivation}

\subsubsection{Beliefs about Consequences}

The parents unanimously agreed that excessive screen time was linked to a myriad of health consequences both in the long and short term. Excessive screen time was attributed to a lowering of IQ, concentration issues, headaches, neck and back problems, laziness as well as dissociation from family. The parents were also concerned with the effects of radiation absorbed after hours of exposure at an age where the brain is still developing. Disruptions to emotional regulation were also cited, linking anger management problems, agitation, and emotional withdrawals to excessive screen time and gaming. Similarly, the mothers identified laziness, excessive weight gain, agitation, and mood disruptions such as depression to a lack of physical activity. Loss of social skills was linked to both excessive screen time and lack of physical activity. Lastly, the parents were cognizant of the social dangers that are mediated through excessive screen time via social media, with unprecedented exposure to a wide variety of influences that could affect adolescent mental, physical, and social health.

\subsubsection{Social/Professional Role and Identity}

Without exception, the parents believed that they had a seminal role in encouraging physical activity and moderating screen time. It was also reported to be easier to encourage PA if the fathers were also active and shared a responsibility in raising an active family. However, they believed such efforts needed to start from an earlier age to ensure a smooth transition when they reached adolescence, which many parents described to be a very difficult process. They also stated that they needed greater support in the face of the COVID-19 pandemic and its long-term implications, which inherently restricted activity and elicited greater opportunities for screen time. The parents acknowledged current government initiatives such as AUD 100 vouchers to encourage sport participation but believed they could do more to ensure more consistent physical activity, considering the expenses of sport clubs such as membership, attire, etc. The parents also highlighted that such vouchers were limited for use with specific associations, whereas they would like to use the voucher to encourage other forms of PA such as purchasing a bike to be ridden in the local area. They underlined the need for schools and local communities to work together and stated that current sports initiatives at schools were basic and only included sports once per week, if any, especially in Islamic schools.

\subsubsection{Goals}

All of the parents maintained that healthy lifestyle behaviours such as engaging in physical activity and reducing screen time was of the utmost priority for a multitude of mental, physical, and social reasons. However, they suggested earlier intervention to be vital to allow older adolescents to foster these habits to be implemented out of their own desire, autonomy, and sense of responsibility towards themselves.

\subsubsection{Optimism}

All of the parents affirmed their confidence in the need for a shift from current physical inactivity and excessive screen time and believed any changes, even if they were small, would be welcomed and would elicit a myriad of health benefits, especially tracking into adulthood. They believed any change that was representative of the inherently 
physical activity lifestyle that the parents themselves enjoyed was vital but were much more optimistic that they could be encouraged and maintained in the context of the current physical and social environment as well as in the COVID-19 pandemic without community, government, and school support.

\subsection{Automatic Motivation}

\subsubsection{Emotion}

The parents relayed their deep fears in attempting to raise their children in a society and environment that promoted laziness, excessive screen time, and lack of movement. Particularly, the mothers were distressed about the effects of the ongoing lockdowns during the pandemic, which isolated adolescents, forcing them to resort to screen devices for connection and kept them indoors. The relationship with screen devices was characterised as "addiction" and was regarded with great disdain. They wished their children could be an inherently physical active generation as they were. The parents identified the long-term consequences of the pandemic, with some children becoming teenagers during this time, a defining period, and were afraid that such excessive screen time and a lack of PA would be deemed to be normal. The parents revealed that their exasperation in failing to limit excessive screen time and encouraging physical activity. They reported having many conflicts with their children, especially over screen time, with time restrictions being placed on devices often leading to severe tantrums and withdrawal symptoms that were similar to those of other "addictions". The parents were highly confident that any reduction in screen time and an increase in physical activity would yield many health benefits. However, they were equally despondent on the current state of adoption of these lifestyle behaviours and pessimistic if change could be implemented, especially for screen time behaviours.

\subsubsection{Reinforcement}

The parents attempted to enforce a routine with children regulating PA and ST to set times after arrival from school on weekdays. Naturally, parents allowed greater access to screen devices and entertainment services on the weekend. The parents did not apply strict rewards or punishments, but many resorted to extreme measures such as turning off the power supply, $\mathrm{Wi}-\mathrm{Fi}$, and confiscating screen devices if the children were deemed to cross limits and enjoy excessive screen time. The parents also confiscated devices as a means of punishment for behaviours that were unrelated to excessive screen use, such as poor academic performance and ethical issues. They did not reward or punish physical activity behaviours.

\subsection{Social Opportunity Social Influences}

The parents emphasised the influence of macroscopic factors such as changes in societal values and the "digital revolution", which forever revolutionised the communications and physical activity landscape. The parents claimed that their era inherently encouraged physical activity due to the safer use of public transport and a lack of screen devices to distract from normal play. There was no need for sports clubs, and incidental activity was more than enough to at least satisfy current physical activity guidelines. The mothers expressed their dismay on the shift of societal values/moral fabric of society and the deterioration of trusted shared spaces in village-like communities, which were primarily responsible for their childhood physical and sport engagement, which is in stark contrast to the current safety concerns in local neighbourhoods. As opposed to a collectivist culture that is representative of the culture practiced amongst their first generation parents and abroad, today's increasingly individualistic culture in conjunction with safety concerns means that parents are much less likely to allow their children to join local activities unchaperoned.

The mothers proclaimed that friends had a great deal of influence on leisure screen time behaviours via the use of electronic devices to access social media and other entertain- 
ment platforms such as YouTube. The mothers were more likely to associate peer pressure in girls, resulting in them participating in telephone calls and Instagram, whereas boys were more likely to partake in shared gaming and entertainment activities on PlayStation ${ }^{\circledR}$ and $\mathrm{Xbox}^{\circledR}$. Influence from friends to join physical activity initiatives was more likely to occur amongst boys, such as gym training for physical stamina for organised sports as well as for enhancing physical appearance. Parents reported a negligible influence from friends on girls.

\subsection{Physical Opportunity \\ Environmental Context and Resources}

The parents reported the presence of government-funded healthy lifestyle programs such as Go4Fun for children aged 7-13 years who were suffering from obesity [34] but complained that such programs were not weight-inclusive or culturally responsive. Furthermore, they stressed the need for such programs to continue throughout high school to target adolescents, citing a dearth of any physical engagement with students and parents outside the mandatory Personal Development, Health, and Physical Education (PDHPE) classes. Some parents did mention after school sports programs run by external organisations but reported high a susceptibility to drop out given school changes and high commitment demands, especially for mothers of more than one adolescent. The mothers defined current Islamic school engagement with sports and physical activity to be rather "tokenistic" and called for the sincerer and more serious incorporation of movement instead of one-off events, especially for girls and for later children in their adolescent years. The parents communicated their concerns for excessive screen time given the shift to online education in light of the COVID-19 pandemic. Many parents described plentiful nearby parks and recreational facilities to encourage engagement in physical activity but also declared safety concerns, especially those hailing from low SES neighbourhoods. Parents only allowed chaperoned visits to the park, which were sometimes limited due to busy schedules. Many attempted to engage their children in organised sports and to become members of sport clubs; however, similarly, the parents reported that this was less likely to be achieved with girls and that the boys that did join eventually left due to lack of interest with older age.

The parents claimed that the physical layout of the home, regardless of size, was not a deterrent for physical activity due to the provision of local parks and facilities. However, the presence of several electronic devices in the household was reported to be linked to a continuous and addictive use of social media. Consequently, the parents resorted to ground rules, as detailed above.

\section{Discussion}

Parents struggle to grapple with the current digitised age and the unprecedented forces that have been exacerbated by the COVID-19 epidemic that limit their ability to mitigate excessive screen time and to encourage physical activity. The parents also expressed deep fears that the current sedentary behaviours that were adopted during COVID-19 would become the norm and worried about long-term consequences for this generation of youth. They reported that physical activity was compromised and a fear for the safety of children travelling alone to neighbourhood parks. Differences by gender were apparent, with older girls being reported to be the least interested in school sports.

One key finding of this study is that despite proximity to parks and other sports facilities, the parents demonstrated extreme reluctance to allow park visitation in their absence. It must be noted that this finding is not unique to ME parents, and while most of the previous literature has concerned children younger than 13 years of age, these concerns are not being voiced by the parents of adolescents as well [35-43]. Reluctance to allow unaccompanied park visits has been reported to be more pronounced in socioeconomically disadvantaged areas. Children who can visit public places unaccompanied do have more park visits [44]. Park and playground features have been shown to be linked to more 
physical activity [45]. Social concerns pertaining to the physical environment were raised regarding neighbourhood safety, fear of crime, and /or stranger danger were also established [46]. A cross-sectional study in the US revealed that the perceived neighbourhood crime rate was linked to children's sedentary behaviour, but this was only found amongst parents from ethnic minorities [47]. Furthermore, a state-wide survey of Australian parents revealed that the perception of a child's competence to travel safely was associated with parental fear, and having a female child and speaking a language other than English was linked to fear of strangers [48]. Parents participating in the Neighbourhood for Active Kids study indicated the need for safer traffic environments to mitigate fears and to further their children's independent mobility [49]. Gender differences have been identified in the US [50,51]. It is important to promote park use by considering evidence showing positive associations between the availability of local parks and playgrounds and youth physical activity, but strategies to enhance safety should be mutually negotiated with communities.

Whilst evidence has shown the need for interventions to target such parental behaviour, the promise for combined school and community interventions [52] hold their appeal to placate fears by utilising school and community physical activity spaces in the presence of trusted community and school personnel. The need for interventions based in the community rather than only the school setting is highlighted given that very few exist in prevention intervention research [8]. The association between BMI and locked schools has also indicated that efforts to halt obesity should include increasing weekend schoolyard accessibility to allow adolescents to play sports [40].

A recent systematic review assessing built environment in programs to promote PA in Latino children and youth highlighted the need to capitalise on social ties and to engage youth in co-creating healthy environments using comprehensive methodological approaches that can address and establish context-specific priorities for each neighbourhood's built environment and promotion of intramural activities [53]. Social Network Analysis (SNA) allows community social networks and norms to be integrated into PA interventions and has been used to assess potential mechanisms to achieve behaviour change. One study demonstrated that different targets in PA interventions (student opinion leaders' vs. sedentary children) can achieve different goals (shift entire distribution of PA vs. increase PA levels in those most affected) [54]. Another purported framework is the Our Voice Model, which allows the engagement of stakeholders, families, and youth as citizen scientists to evaluate local social and environmental factors influencing PA participation in "real-time" using an application [55]. This has been found to strengthen community efficacy and the ownership of changing behaviours and their local environments and advocacy for a change in policies [56]. Such design would allow further comprehensive mapping and the consideration of factors such as street connectivity, which has been linked to PA [57]. One such project is being undertaken with adolescents from low-income neighbourhoods from multi-ethnic backgrounds in Sweden. The framework allowed adolescents to identify local features that promoted or prevented physical activity, the findings of which are being used to appeal to local decision and policy makers to improve local neighbourhoods to promote PA according to their specific needs [58,59].

There is emerging evidence that a school-based intervention integrated with health promotion activities yields positive results across green space use and competence, dietary habits, and resistance to substance use [60]. Green space interventions have shown potential to increase physical activity levels [61] and to lower BMI and prevalence of overweight [62], which makes it a possible effective design to be targeted in the future, given the nature of lifestyle behaviours such as diet and physical activity to cluster together. Indirect parental involvement is needed in the design of such interventions, as this study has shown that they exact influence over an adolescent's opportunity for PA, as displayed in another study [63].

This is of particular importance given the documented link between a lack of physical activity and an increase in sedentary time because of increased screen time and emerging obesity. Focusing on community and sports initiatives in conjunction with advocating for 
specific policies targeting lower socioeconomic areas given higher fears of crime which limit children's independent mobility is vital and will not only yield improvement in PA levels but will decrease sedentary time. There is evidence demonstrating that crime, a lack of quality sporting facilities, or neighbourhood options for physical activity may contribute to greater TV viewing among youth $[64,65]$. It was also shown that a school environment that promoted health policies, upheld mobile phone bans, and provided more time for physical education classes was associated with lower sedentary time and higher PA levels [66].

Excessive screen time was identified to be a significant precursor for parental frustration and worry, given its prevalent use in an inherently screen-dominated society. Its implications for health and its influence on increased sedentary behaviour and decreased physical activity was concerning. Whilst some parents were able to maintain routines and rules that guided screen use, the majority were unable to exact influence, and unlike for other behaviours, conflicts regarding screen time were more likely to be confrontational. This was demonstrated in a previous qualitative study which showed that parents felt able to limit adolescent access to sugary drink consumption but felt unable to yield control over adolescent screen time [67]. This is not surprising given its ubiquitous use, with $97 \%$ of Australian households with children aged less than 15 years having access to internet and with $91 \%$ of connected households sporting desktop or laptop computers, mobiles, and smart phones. Adolescents aged 15 to 17 years old were the highest proportion of internet users (98\%) in Australia [68]. Parents complained COVID-19 heightened screen time, something that has also been reported by other authors [69,70]. The absence of screen rules amongst adolescents has been linked to overweight and obesity [20].

Several parallels were identified between the findings of this study and those of focus groups held with adolescents in a previous exploratory study by our research group [32]. In the current study, the parents revealed that boys were much more likely to be involved in sport and that girls were more likely to grow disinterested as they become older. The parents also communicated the lack of serious opportunities for continuous engagement in sports in schools, especially in Islamic schools, in particular for girls and older adolescents [71]. This was corroborated by the frustration that was expressed by adolescent girls regarding a lack of sporting initiatives and the experience of being denied access to sports facilities. Both attributed this experience to the "tokenistic" sports engagement Islamic schools that has been demonstrated [32]. The parents explained that schools place a greater focus on academia and neglect extracurricular activities. This interaction between culture and gender was also seen in immigrant families in a qualitative study that explored the influence of family values and traditions on adolescent physical activity in Qatar [72]. Acculturation and the influence of culture has been identified as having an influence on physical activity levels in Arab immigrant populations, but this has been largely restricted to adult audiences $[73,74]$ and cannot be applied to adolescents who are usually second and third generation citizens of the host country.

To circumvent a lack of school opportunities, most parents enlisted their children into sporting clubs, which has been shown to contribute significantly to leisure PA [75]. However, such options only further widen socioeconomic disparities with barriers such as cost, accessibility, and lack of local facilities affecting families from the most disadvantaged backgrounds [76,77], something that was also identified by the parents in this research. A recent analysis has also shown that SES is inversely linked with sports expenditure, with an AUD 311 difference in median expenditure between the most and least disadvantaged populations [78]. However, the implementation of the Active Kids Voucher program in NSW is a clear demonstration of the power of upstream policies and programs to support physical activity participation. The provision of an AUD 100 voucher to cover the cost of structured physical activity registration was shown to increase the number of days physical activity guidelines were achieved, showing an increase from 4.0 days per week to 4.9 days per week after 6 months [79]. Moreover, it contributed to $42.4 \%$ of the total PA time per week and made a greater contribution to adolescents who were 15-18 years of age, spoke a 
language other than English, lived in lower SES areas, or who were obese [79]; however, it was shown that these programs were less likely to reach them $[80,81]$. The program is currently undergoing further evaluation [82], but the results to date suggest that these groups demand additional interventions to ensure that equitable benefits are reaped from such initiatives [83].

\section{Study Strengths and Limitations}

This study possesses several strengths, including the rich and detailed data that were obtained using semi-structured interviews and the individual completion of the coding process by two researchers, which was then cross checked and overseen with a third in order to discuss and agree on themes. Among the limitations of the present study is the inability to capture paternal influence, as all of the interviews were conducted with mothers even though most of the families comprised two parents. Fathers also play a pivotal role in shaping adolescent physical activity behaviours [84]. Lastly, a majority of the mothers were from Lebanese backgrounds, and opinions of ME parents from other backgrounds may differ.

\section{Conclusions}

The findings of this demonstrate the need for intersectoral efforts across public health specialists, community organisations, and schools to deliver targeted real-world interventions that carry contextualised and culture-tailored messages. The interviews revealed that the majority of our participants were from the Islamic faith and of a Lebanese background. The need for interventions to be community-driven and inclusive of other subgroups within the ME community were recognized. Such efforts need to be complimented with upstream policies and public sector financial incentives to further reduce socio economic gaps in PA participation. The findings of this research reveal that Islamic schools may need to incorporate long-term sports programs, especially for girls. Further initiatives should centre on localised youth-driven approaches that aim to assess the local environment to inform context- and neighbourhood-specific interventions. Gender-specific and age-appropriate interventions should be prioritised to increase opportunities for girls and older adolescents, given their lack of PA worldwide [84].

Author Contributions: Conceptualization, N.H. and M.A.-F.; methodology, N.H. and M.A.-F.; formal analysis, N.H., Y.S. and M.A.-F.; writing-original draft preparation, N.H.; writing-review and editing, Y.S. and M.A.-F. All authors have read and agreed to the published version of the manuscript.

Funding: N.H. is a PhD candidate at the University of Sydney and currently holds a postgraduate research training scholarship. Y.S. holds a PhD scholarship from the China Scholarship Council. No specific funding was provided for this study.

Institutional Review Board Statement: The study was conducted according to the guidelines of the Declaration of Helsinki and was approved by the Human Research Ethics Committee (HREC) at the University of Sydney (2020/708) on 2 November 2020.

Informed Consent Statement: Informed consent was obtained from all subjects involved in the study.

Data Availability Statement: Due to privacy reasons in ethics, we cannot make the data publicly available, but please contact author if further information is required.

Acknowledgments: The authors would like to thank all of the Middle-Eastern parents who participated in this study.

Conflicts of Interest: M.A.-F. has received funding from the Australian Research Council, National Health and Medical Research Council, NSW Health, and Cancer Council NSW for other studies in the past three years but not this study. All of the authors report no financial or personal conflict of interest. 


\section{References}

1. Ward, Z.J.; Long, M.W.; Resch, S.C.; Giles, C.M.; Cradock, A.L.; Gortmaker, S.L. Simulation of Growth Trajectories of Childhood Obesity into Adulthood. N. Engl. J. Med. 2017, 377, 2145-2153. [CrossRef] [PubMed]

2. Ogden, C.L.; Fryar, C.D.; Hales, C.; Carroll, M.D.; Aoki, Y.; Freedman, D.S. Differences in Obesity Prevalence by Demographics and Urbanization in US Children and Adolescents, 2013-2016. JAMA 2018, 319, 2410-2418. [CrossRef]

3. Ogden, C.L.; Carroll, M.D.; Fakhouri, T.H.; Hales, C.M.; Fryar, C.D.; Li, X.; Freedman, D.S. Prevalence of Obesity Among Youths by Household Income and Education Level of Head of Household-United States 2011-2014. MMWR Morb. Mortal. Wkly. Rep. 2018, 67, 186-189. [CrossRef] [PubMed]

4. Ogden, C.L.; Carroll, M.D.; Lawman, H.G.; Fryar, C.D.; Kruszon-Moran, D.; Kit, B.K.; Flegal, K.M. Trends in Obesity Prevalence Among Children and Adolescents in the United States, 1988-1994 Through 2013-2014. JAMA 2016, 315, 2292-2299. [CrossRef] [PubMed]

5. Stennett, M.; Blokland, A.; Watt, R.G.; Heilmann, A. Mid-adolescent ethnic variations in overweight prevalence in the UK Millennium Cohort Study. Eur. J. Public Health 2021, 31, 396-402. [CrossRef] [PubMed]

6. Hardy, L.L.; Jin, K.; Mihrshahi, S.; Ding, D. Trends in overweight, obesity, and waist-to-height ratio among Australian children from linguistically diverse backgrounds, 1997 to 2015. Int. J. Obes. 2018, 43, 116-124. [CrossRef]

7. Hayba, N.; Elkheir, S.; Hu, J.; Allman-Farinelli, M. Effectiveness of Lifestyle Interventions for Prevention of Harmful Weight Gain among Adolescents from Ethnic Minorities: A Systematic Review. Int. J. Environ. Res. Public Health 2020, 17, 6059. [CrossRef]

8. Hayba, N.; Rissel, C.; Farinelli, M.A. Effectiveness of lifestyle interventions in preventing harmful weight gain among adolescents: A systematic review of systematic reviews. Obes. Rev. 2020, 22. [CrossRef]

9. Hardy, L.L.; Mihrshahi, S.; Drayton, B.A.; Bauman, A. NSW Schools Physical Activity and Nutrition Survey (SPANS) 2015: Full Report; NSW Department of Health: Sydney, Australia, 2015.

10. Evenson, K.R.; Arredondo, E.M.; Carnethon, M.R.; Delamater, A.M.; Gallo, L.C.; Isasi, C.R.; Perreira, K.M.; Foti, S.A.; Van Horn, L.; Vidot, D.C.; et al. Physical Activity and Sedentary Behavior among US Hispanic/Latino Youth: The SOL Youth Study. Med. Sci. Sports Exerc. 2019, 51, 891-899. [CrossRef]

11. Hayes, G.; Dowd, K.P.; MacDonncha, C.; Donnelly, A. Tracking of Physical Activity and Sedentary Behavior From Adolescence to Young Adulthood: A Systematic Literature Review. J. Adolesc. Health 2019, 65, 446-454. [CrossRef]

12. Hruby, A.; Hu, F.B. The Epidemiology of Obesity: A Big Picture. Pharmacoeconomics 2014, 33, 673-689. [CrossRef] [PubMed]

13. Gopinath, B.; A Baur, L.; Hardy, L.L.; Kifley, A.; A Rose, K.; Wong, T.Y.; Mitchell, P. Relationship between a range of sedentary behaviours and blood pressure during early adolescence. J. Hum. Hypertens. 2011, 26, 350-356. [CrossRef] [PubMed]

14. Alberga, A.S.; Sigal, R.J.; Goldfield, G.; Homme, D.P.; Kenny, G.P. Overweight and obese teenagers: Why is adolescence a critical period? Pediatr. Obes. 2012, 7, 261-273. [CrossRef]

15. Hou, X.; Liu, J.-M.; Tang, Z.-Y.; Ruan, B.; Cao, X.-Y. The Gender Difference in Association between Home-Based Environment and Different Physical Behaviors of Chinese Adolescents. Int. J. Environ. Res. Public Health 2020, 17, 8120. [CrossRef] [PubMed]

16. Beets, M.W.; Cardinal, B.J.; Alderman, B. Parental Social Support and the Physical Activity-Related Behaviors of Youth: A Review. Health Educ. Behav. 2010, 37, 621-644. [CrossRef]

17. Pugliese, J.; Tinsley, B. Parental socialization of child and adolescent physical activity: A meta-analysis. J. Fam. Psychol. 2007, 21, 331-343. [CrossRef]

18. Mendonça, G.; Cheng, L.A.; Mélo, E.N.; de Farias Júnior, J.C. Physical activity and social support in adolescents: A systematic review. Health Educ. Res. 2014, 29, 822-839. [CrossRef]

19. Laird, Y.; Fawkner, S.; Kelly, P.; McNamee, L.; Niven, A. The role of social support on physical activity behaviour in adolescent girls: A systematic review and meta-analysis. Int. J. Behav. Nutr. Phys. Act. 2016, 13, 79. [CrossRef]

20. Mihrshahi, S.; Drayton, B.A.; Bauman, A.E.; Hardy, L.L. Associations between childhood overweight, obesity, abdominal obesity and obesogenic behaviors and practices in Australian homes. BMC Public Health 2017, 18, 44. [CrossRef]

21. Michie, S.; Van Stralen, M.M.; West, R. The behaviour change wheel: A new method for characterising and designing behaviour change interventions. Implement. Sci. 2011, 6, 42. [CrossRef]

22. Cane, J.; O'Connor, D.; Michie, S. Validation of the theoretical domains framework for use in behaviour change and implementation research. Implement. Sci. 2012, 7, 37. [CrossRef] [PubMed]

23. Hayba, N.; Khalil, C.; Allman-Farinelli, M. Enabling Better Nutrition and Physical Activity for Adolescents from Middle Eastern Backgrounds: Focus Groups. Nutrients 2021, 13, 3007. [CrossRef]

24. Guba, E.G. Criteria for assessing the trustworthiness of naturalistic inquiries. ECTJ 1981, 29, 75-91. [CrossRef]

25. May, C. More semi than structured? Some problems with qualitative research methods. Nurse Educ. Today 1996, 16, 189-192. [CrossRef]

26. Tong, A.; Sainsbury, P.; Craig, J. Consolidated criteria for reporting qualitative research (COREQ): A 32-item checklist for interviews and focus groups. Int. J. Qual. Health Care 2007, 19, 349-357. [CrossRef]

27. Michie, S.; West, R.; Campbell, R.; Brown, J.; Gainforth, H. ABC of Behaviour Change Theories; Silverback Publishing: Sutton, UK, 2014.

28. Francis, J.J.; O'Connor, D.; Curran, J. Theories of behaviour change synthesised into a set of theoretical groupings: Introducing a thematic series on the theoretical domains framework. Implement. Sci. 2012, 7, 35. [CrossRef] 
29. Michie, S.; Johnston, M.; Abraham, C.; Lawton, R.; Parker, D.; Walker, A. Making psychological theory useful for implementing evidence based practice: A consensus approach. Qual. Saf. Health Care 2005, 14, 26-33. [CrossRef]

30. Australian Bureau of Statistics. SEIFA by Postal Area Code (POA); Australian Bureau of Statistics: Canberra, Australia, 2021. Available online: https://stat.data.abs.gov.au/Index.aspx?DataSetCode=SEIFA_POA (accessed on 10 October 2021).

31. Atkins, L.; Francis, J.; Islam, R.; O'Connor, D.; Patey, A.; Ivers, N.; Foy, R.; Duncan, E.; Colquhoun, H.; Grimshaw, J.M.; et al. A guide to using the Theoretical Domains Framework of behaviour change to investigate implementation problems. Implement. Sci. 2017, 12, 77. [CrossRef] [PubMed]

32. Braun, V.; Clarke, V. To saturate or not to saturate? Questioning data saturation as a useful concept for thematic analysis and sample-size rationales. Qual. Res. Sport Exerc. Health 2019, 13, 201-216. [CrossRef]

33. Welsby, D.; Nguyen, B.; O’Hara, B.J.; Innes-Hughes, C.; Bauman, A.; Hardy, L.L. Process evaluation of an up-scaled community based child obesity treatment program: NSW Go4Fun ${ }^{\circledR}$. BMC Public Health 2014, 14, 140. [CrossRef]

34. Ayllón, E.; Moyano, N.; Lozano, A.; Cava, M.-J. Parents' Willingness and Perception of Children's Autonomy as Predictors of Greater Independent Mobility to School. Int. J. Environ. Res. Public Health 2019, 16, 732. [CrossRef] [PubMed]

35. Kim, Y.-J.; Lee, C. Built and Natural Environmental Correlates of Parental Safety Concerns for Children's Active Travel to School. Int. J. Environ. Res. Public Health 2020, 17, 517. [CrossRef] [PubMed]

36. Lindsay, A.C.; Sussner, K.M.; Greaney, M.L.; Peterson, K.E. Influence of Social Context on Eating, Physical Activity, and Sedentary Behaviors of Latina Mothers and Their Preschool-Age Children. Health Educ. Behav. 2006, 36, 81-96. [CrossRef]

37. Mier, N.; Lee, C.; Smith, M.L.; Wang, X.; Irizarry, D.; Avila-Rodriguez, E.H.; Trevino, L.; Ory, M.G. Mexican-American children's perspectives: Neighborhood characteristics and physical activity in Texas-Mexico border colonias. J. Environ. Health 2013, 76, 8-16. [PubMed]

38. Olvera, N.; Smith, D.W.; Lee, C.; Liu, J.; Lee, J.; Kellam, S.; Kim, J.-H. Hispanic maternal and children's perceptions of neighborhood safety related to walking and cycling. Health Place 2012, 18, 71-75. [CrossRef] [PubMed]

39. Schoeppe, S.; Duncan, M.J.; Badland, H.M.; Alley, S.; Williams, S.; Rebar, A.L.; Vandelanotte, C. Socio-demographic factors and neighbourhood social cohesion influence adults' willingness to grant children greater independent mobility: A cross-sectional study. BMC Public Health 2015, 15, 690. [CrossRef]

40. Scott, M.M.; Cohen, D.A.; Evenson, K.R.; Elder, J.; Catellier, D.; Ashwood, J.S.; Overton, A. Weekend schoolyard accessibility, physical activity, and obesity: The Trial of Activity in Adolescent Girls (TAAG) study. Prev. Med. 2007, 44, 398-403. [CrossRef]

41. Veitch, J.; Ball, K.; Rivera, E.; Loh, V.; Deforche, B.; Timperio, A. Understanding children's preference for park features that encourage physical activity: An adaptive choice based conjoint analysis. Int. J. Behav. Nutr. Phys. Act. 2021, 18, 133. [CrossRef]

42. Vlaar, J.; Brussoni, M.; Janssen, I.; Mâsse, L.C. Roaming the Neighbourhood: Influences of Independent Mobility Parenting Practices and Parental Perceived Environment on Children's Territorial Range. Int. J. Environ. Res. Public Health 2019, 16, 3129. [CrossRef]

43. Veitch, J.; Carver, A.; Hume, C.; Crawford, D.; Timperio, A.; Ball, K.; Salmon, J. Are independent mobility and territorial range associated with park visitation among youth? Int. J. Behav. Nutr. Phys. Act. 2014, 11, 73. [CrossRef]

44. Edwards, N.; Hooper, P.; Knuiman, M.; Foster, S.; Giles-Corti, B. Associations between park features and adolescent park use for physical activity. Int. J. Behav. Nutr. Phys. Act. 2015, 12, 21. [CrossRef]

45. Marzi, I.; Demetriou, Y.; Reimers, A.K. Social and physical environmental correlates of independent mobility in children: A systematic review taking sex/gender differences into account. Int. J. Health Geogr. 2018, 17, 24. [CrossRef] [PubMed]

46. Budd, E.L.; Hipp, J.A.; Geary, N.; Dodson, E.A. Racial differences in parental perceptions of the neighborhood as predictors of children's physical activity and sedentary behavior. Prev. Med. Rep. 2015, 2, 397-402. [CrossRef]

47. Bennetts, S.K.; Cooklin, A.R.; Crawford, S.; D’Esposito, F.; Hackworth, N.J.; Green, J.; Matthews, J.; Strazdins, L.; Zubrick, S.; Nicholson, J.M. What Influences Parents' Fear about Children's Independent Mobility? Evidence from a State-Wide Survey of Australian Parents. Am. J. Health Promot. 2017, 32, 667-676. [CrossRef]

48. Smith, M.; Amann, R.; Cavadino, A.; Raphael, D.; Kearns, R.; Mackett, R.; Mackay, L.; Carroll, P.; Forsyth, E.; Mavoa, S.; et al. Children's Transport Built Environments: A Mixed Methods Study of Associations between Perceived and Objective Measures and Relationships with Parent Licence for Independent Mobility in Auckland, New Zealand. Int. J. Environ. Res. Public Health 2019, 16, 1361. [CrossRef] [PubMed]

49. Cohen, D.A.; Han, B.; Williamson, S.; Nagel, C.; McKenzie, T.L.; Evenson, K.R.; Harnik, P. Playground features and physical activity in U.S. neighborhood parks. Prev. Med. 2020, 131, 105945. [CrossRef]

50. Cohen, D.A.; Williamson, S.; Han, B. Gender Differences in Physical Activity Associated with Urban Neighborhood Parks: Findings from the National Study of Neighborhood Parks. Women's Health Issues 2020, 31, 236-244. [CrossRef] [PubMed]

51. Ball, K.; Carver, A.; Downing, K.; Jackson, M.; O’Rourke, K. Addressing the social determinants of inequities in physical activity and sedentary behaviours. Health Promot. Int. 2015, 30, ii8-ii19. [CrossRef] [PubMed]

52. Sarmiento, O.L.; Rubio, M.A.; King, A.C.; Serrano, N.; Hino, A.A.F.; Hunter, R.F.; Aguilar-Farias, N.; Parra, D.C.; Salvo, D.; Jáuregui, A.; et al. Built environment in programs to promote physical activity among Latino children and youth living in the United States and in Latin America. Obes. Rev. 2021, 22, e13236. [CrossRef]

53. Zhang, J.; Shoham, D.A.; Tesdahl, E.; Gesell, S.B. Network interventions on physical activity in an afterschool program: An agent-based social network study. Am. J. Public Health 2015, 105, S236-S243. [CrossRef] 
54. King, A.C.; Winter, S.J.; Sheats, J.L.; Rosas, L.G.; Buman, M.P.; Salvo, D.; Rodriguez, N.M.; Seguin, R.A.; Moran, M.; Garber, R.; et al. Leveraging Citizen Science and Information Technology for Population Physical Activity Promotion. Transl. J. ACSM 2016, 1, 30-44. [CrossRef]

55. King, A.; Odunitan-Wayas, F.; Chaudhury, M.; Rubio, M.; Baiocchi, M.; Kolbe-Alexander, T.; Montes, F.; Banchoff, A.; Sarmiento, O.; Bälter, K.; et al. Community-Based Approaches to Reducing Health Inequities and Fostering Environmental Justice through Global Youth-Engaged Citizen Science. Int. J. Environ. Res. Public Health 2021, 18, 892. [CrossRef] [PubMed]

56. Jia, P.; Zou, Y.; Wu, Z.; Zhang, D.; Wu, T.; Smith, M.; Xiao, Q. Street connectivity, physical activity, and childhood obesity: A systematic review and meta-analysis. Obes. Rev. 2019, 22, e12943. [CrossRef] [PubMed]

57. Bälter, K.; Rydenstam, T.; Fell, T.; King, A.C.; Buli, B.G. Data from an Our Voice citizen science initiative in neighborhoods with low socioeconomic status in Sweden: A proof of concept for collecting complex data. Data Brief 2020, 33, 106394. [CrossRef]

58. Rydenstam, T.; Fell, T.; Buli, B.G.; King, A.C.; Bälter, K. Using citizen science to understand the prerequisites for physical activity among adolescents in low socioeconomic status neighborhoods-The NESLA study. Health Place 2020, 65, 102387. [CrossRef]

59. Kwok, S.W.H.; Wu, C.S.T.; Tong, H.T.; Ni Ho, C.; Leung, K.L.; Leung, Y.C.P.; Lui, K.C.; Wong, C.K.C. Effects of the School-Based Integrated Health Promotion Program with Hydroponic Planting on Green Space Use and Satisfaction, Dietary Habits, and Mental Health in Early Adolescent Students: A Feasibility Quasi-Experiment. Front. Public Health 2021, 9, 1384. [CrossRef]

60. James, P.; Banay, R.F.; Hart, J.E.; Laden, F. A Review of the Health Benefits of Greenness. Curr. Epidemiol. Rep. 2015, 2, 131-142. [CrossRef] [PubMed]

61. Utter, J.; Denny, S.; Dyson, B. School gardens and adolescent nutrition and BMI: Results from a national, multilevel study. Prev. Med. 2016, 83, 1-4. [CrossRef]

62. Verloigne, M.; Veitch, J.; Carver, A.; Salmon, J.; Cardon, G.; De Bourdeaudhuij, I.; Timperio, A. Exploring associations between parental and peer variables, personal variables and physical activity among adolescents: A mediation analysis. BMC Public Health 2014, 14, 966. [CrossRef] [PubMed]

63. Gebremariam, M.K.; Henjum, S.; Terragni, L.; Torheim, L.E. Correlates of screen time and mediators of differences by parental education among adolescents. BMC Pediatr. 2020, 20, 279. [CrossRef]

64. Timperio, A.; Salmon, J.; Ball, K.; Velde, S.J.T.; Brug, J.; Crawford, D. Neighborhood characteristics and TV viewing in youth: Nothing to do but watch TV? J. Sci. Med. Sport 2012, 15, 122-128. [CrossRef]

65. Nyberg, G.; Ekblom, Ö.; Kjellenberg, K.; Wang, R.; Larsson, H.; Jakobsson, B.T.; Helgadóttir, B. Associations between the School Environment and Physical Activity Pattern during School Time in Swedish Adolescents. Int. J. Environ. Res. Public Health 2021, 18, 10239. [CrossRef]

66. A Hattersley, L.; A Shrewsbury, V.; A King, L.; A Howlett, S.; Hardy, L.L.; A Baur, L. Adolescent-parent interactions and attitudes around screen time and sugary drink consumption: A qualitative study. Int. J. Behav. Nutr. Phys. Act. 2009, 6, 61. [CrossRef] [PubMed]

67. Australian Bureau of Statistics. Household Use of Information Technology; Australian Bureau of Statistics: Canberra, Australia, 2018. Available online: https:/ / www.abs.gov.au/statistics/industry/technology-and-innovation/household-use-informationtechnology / latest-release (accessed on 10 October 2021).

68. Schmidt, S.C.E.; Anedda, B.; Burchartz, A.; Eichsteller, A.; Kolb, S.; Nigg, C.; Niessner, C.; Oriwol, D.; Worth, A.; Woll, A. Physical activity and screen time of children and adolescents before and during the COVID-19 lockdown in Germany: A natural experiment. Sci. Rep. 2020, 10, 21780. [CrossRef] [PubMed]

69. Kołota, A.; Głąbska, D. COVID-19 Pandemic and Remote Education Contributes to Improved Nutritional Behaviors and Increased Screen Time in a Polish Population-Based Sample of Primary School Adolescents: Diet and Activity of Youth during COVID-19 (DAY-19) Study. Nutrients 2021, 13, 1596. [CrossRef]

70. Mikalsen, H.K.; Bentzen, M.; Säfvenbom, R.; Lagestad, P.A. Trajectories of Physical Activity Among Adolescents in the Transition From Primary to Secondary School. Front. Sports Act. Living 2020, 2, 85. [CrossRef]

71. Aljayyousi, G.F.; Abu Munshar, M.; Al-Salim, F.; Osman, E.R. Addressing context to understand physical activity among Muslim university students: The role of gender, family, and culture. BMC Public Health 2019, 19, 1452. [CrossRef] [PubMed]

72. Elshahat, S.; Newbold, K.B. Physical activity participation among Arab immigrants and refugees in Western societies: A scoping review. Prev. Med. Rep. 2021, 22, 101365. [CrossRef] [PubMed]

73. El Masri, A.; Kolt, G.S.; George, E.S. A systematic review of qualitative studies exploring the factors influencing the physical activity levels of Arab migrants. Int. J. Behav. Nutr. Phys. Act. 2021, 18, 2. [CrossRef] [PubMed]

74. Eime, R.; Sawyer, N.; Harvey, J.; Casey, M.; Westerbeek, H.; Payne, W. Integrating public health and sport management: Sport participation trends 2001-2010. Sport Manag. Rev. 2014, 18, 207-217. [CrossRef]

75. Hardy, L.L.; Kelly', B.; Chapman, K.; King, L.; Farrell, L. Parental perceptions of barriers to children's participation in organised sport in Australia. J. Paediatr. Child Health 2010, 46, 197-203. [CrossRef]

76. Christian, D.; Todd, C.; Hill, R.; Rance, J.; Mackintosh, K.; Stratton, G.; Brophy, S. Active children through incentive vouchersEvaluation (ACTIVE): A mixed-method feasibility study. BMC Public Health 2016, 16, 890. [CrossRef]

77. Reece, L.J.; McInerney, C.; Blazek, K.; Foley, B.C.; Schmutz, L.; Bellew, B.; Bauman, A.E. Reducing financial barriers through the implementation of voucher incentives to promote children's participation in community sport in Australia. BMC Public Health 2020, 20, 19. [CrossRef] 
78. Foley, B.C.; Owen, K.B.; Bauman, A.E.; Bellew, W.; Reece, L.J. Effects of the Active Kids voucher program on children and adolescents' physical activity: A natural experiment evaluating a state-wide intervention. BMC Public Health 2021, $21,22$. [CrossRef] [PubMed]

79. Foley, B.C.; Owen, K.B.; Bellew, W.; Wolfenden, L.; Reilly, K.; Bauman, A.E.; Reece, L.J. Physical Activity Behaviors of Children Who Register for the Universal, State-Wide Active Kids Voucher: Who Did the Voucher Program Reach? Int. J. Environ. Res. Public Health 2020, 17, 5691. [CrossRef]

80. Owen, K.B.; Foley, B.C.; Bauman, A.; Bellew, B.; Reece, L.J. Parental awareness and engagement in the Active Kids program across socioeconomic groups. J. Sci. Med. Sport 2020, 23, 753-757. [CrossRef] [PubMed]

81. Reece, L.; Foley, B.; Bellew, W.; Owen, K.; Cushway, D.; Srinivasan, N.; Hamdorf, P.; Bauman, A. Active Kids: Evaluation protocol for a universal voucher program to increase children's participation in organised physical activity and sport. Public Health Res. Pract. 2020, 31, e30122006. [CrossRef] [PubMed]

82. Virgona, N.; Foley, B.C.; Ryan, H.; Nolan, M.; Reece, L. 'One hundred dollars is a big help, but to continue, it's a challenge': A qualitative study exploring correlates and barriers to Active Kids voucher uptake in western Sydney. Health Promot. J. Aust. 2021. [CrossRef] [PubMed]

83. Zhang, Y.; Hurtado, G.A.; Flores, R.; Alba-Meraz, A.; Reicks, M. Latino Fathers' Perspectives and Parenting Practices Regarding Eating, Physical Activity, and Screen Time Behaviors of Early Adolescent Children: Focus Group Findings. J. Acad. Nutr. Diet. 2018, 118, 2070-2080. [CrossRef] [PubMed]

84. van Sluijs, E.M.F.; Ekelund, U.; Crochemore-Silva, I.; Guthold, R.; Ha, A.; Lubans, D.; Oyeyemi, A.L.; Ding, D.; Katzmarzyk, P.T. Physical activity behaviours in adolescence: Current evidence and opportunities for intervention. Lancet 2021, 398, 429-442. [CrossRef] 